\title{
Facilitating Effective Communication Between First Responders and \\ Older Adults During Fall Incidents
}

DOMINICAN

UNIVERSITY of CALIF ORNIA
By: Krystin Beeman, Erica Berger, Isabel Cabazes, Nicole Mathews Faculty Advisor: Ruth Ramsey, Ed.D, OTR/L

Dominican University of California, Department of Occupational Therapy

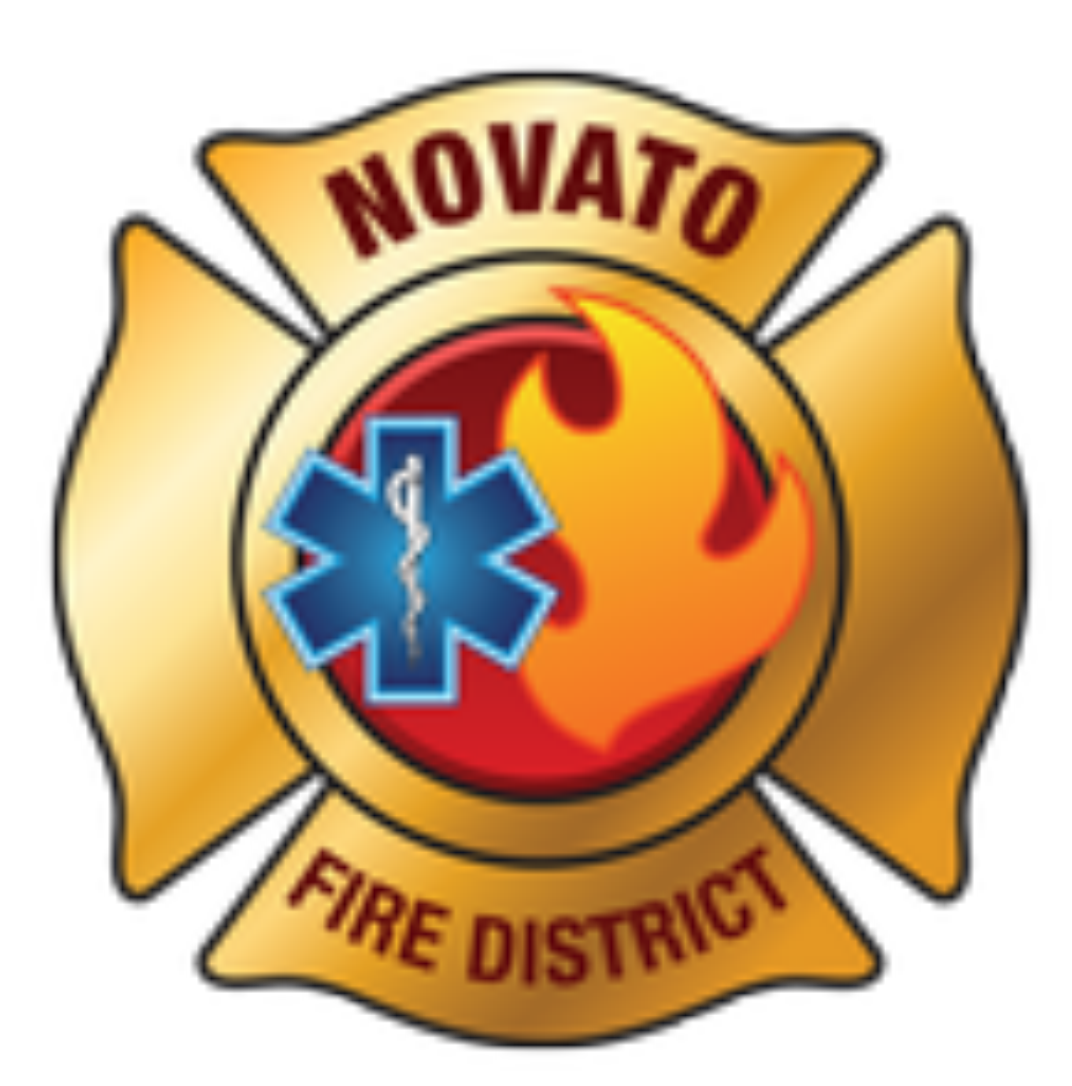

\section{Introduction}

-Falls are a major public health issue for older adults

-First responders (FR) often assist OA fallers (Pressman, Piertryzyk, \&

Schneider, 2011)

- Occupational therapists can help FR's work more effectively with OA's

during fall incidents, and also help prevent future falls

\section{Literature Review}

Falls in Older Adults

-1:3 individuals 65 or older falls each year in USA (CDC, 2013)

-OA's prone to falls due to age-related physical changes and disease processes (Rubenstein, 2006)

Communication Needs of Older Adults

- OA's often have decreased abilities to communicate effectively due to

decline in physical health and cognitive function, including memory

(Baylor et al., 2010)

- FR's must be able to effectively communicate to assess and administer proper care to OA's, especially during a fall incident (Elmqvist, Fridlund \& Ekeberg, 2008)

First Responders \& Older Adults

-FR receive 17.4 million calls per year for OA's (Jacobson et al., 2012)

-1:12 calls are OA's who have fallen (Rattue, 2012)

First Responders \& Occupational Therapists

-OT's provide assessment, training, and support to help prevent falls in OA's (AOTA, 2013)

-OT's can establish and implement community-based fall prevention programs for clients at risk of falling or who have already fallen


\section{Project Purpose}

-Educate FR's re: needs of OA's during fall incidents -Improve communication skills of FR's with OA's

-Improve quality of interactions, between FR's and OA's

-Provide FR's with referral sources for OA fallers and their families

\section{Project Implementation}

Format

-Educational presentations to Novato Fire Department (NFD)

- 2 hours each, presented to all shifts at NFD (6X)

Methods

-Lecture, PowerPoint, series of "drills" or role play, discussion

Topics

-Role of OT in fall prevention, statistics re: OA's \& challenges of aging

information about fall-risk factors, communication deficits of OA's, especially those with Alzheimer's \& dementia, hearing loss, polypharmacy, nutrition, effective communication strategies -Brochure with additional resources for FP

\section{Evaluation \& Recommendations}

$.95 \%$ of participants satisfied with presentation

• Humor helped build rapport with FR's

- Recommend giving presentations to other fire districts

- Give presentations in classroom settings to $\uparrow$ participant engagement

Collaboration between FR's and OT's can improve communication during fall incidents, help decrease falls in $O A$ "s, and establish new roles for OT in community health and fall prevention.

\section{References}

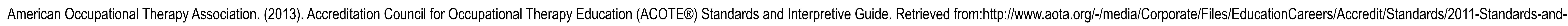

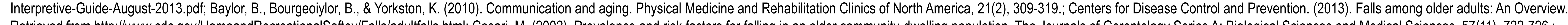

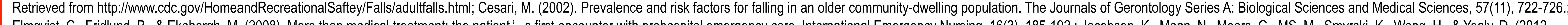

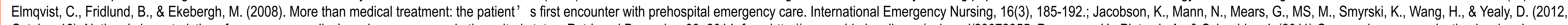




243590.php.; Rubenstein, L., \& Josephson, K. (2002). The epidemiology of falls and syncope. Clinics in Geriatric Medicine, 141-158. Retrieved October 5, 2014. 